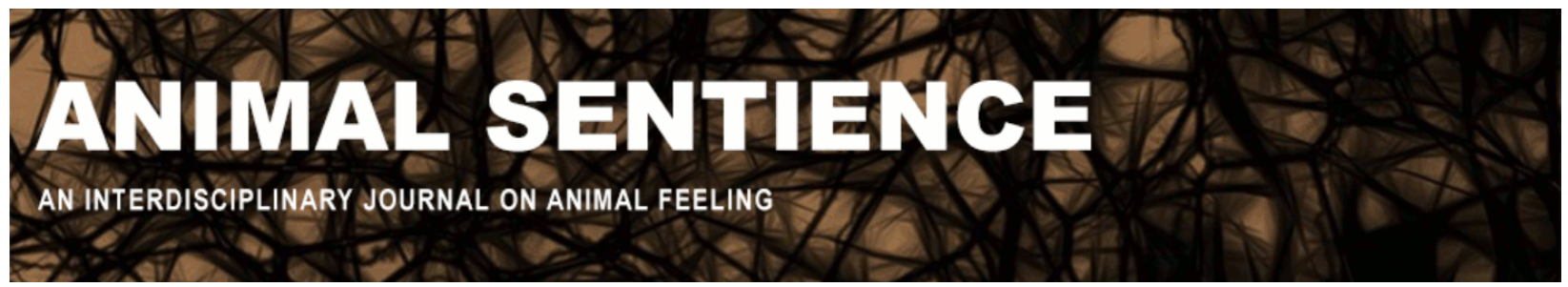

Edelman, Shimon; Moyal, Roy; and Fekete, Tomer (2016) To bee or not to bee?. Animal Sentience 9(14)

DOI: $10.51291 / 2377-7478.1148$

Date of submission: 2016-08-17

Date of acceptance: 2016-08-19

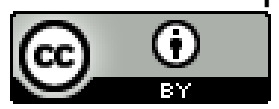

This article has appeared in the journal Animal

Sentience, a peer-reviewed journal on animal

cognition and feeling. It has been made open access,

free for all, by WellBeing International and deposited

in the WBI Studies Repository. For more information,

please contact

wbisr-info@wellbeingintl.org.

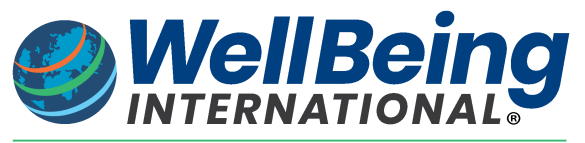

SOLUTIONS FOR PEOPLE, ANIMALS AND ENVIRONMENT 


\title{
To bee or not to bee?
}

Commentary on Klein \& Barron on Insect Experience

\author{
Shimon Edelman \\ Roy Moyal \\ Department of Psychology, Cornell University \\ Tomer Fekete \\ Department of Psychology, KU Leuven, Belgium
}

\begin{abstract}
Klein \& Barron's (2016) (K \& B's) case for insect consciousness is a welcome development in an area that, in all of the science and philosophy of mind, is probably the most anthropocentric. In this commentary, we seek to strengthen K \& B's side of the argument by appealing not just to putative neural mechanisms but also to computational theory that supports it (section 1 ). We also offer some remarks on three distinctions that are relevant to $\mathrm{K} \& \mathrm{~B}$ 's thesis and are central to phenomenal awareness: between the capacity for awareness and its contents (section 2); between awareness and selfhood (section $\underline{3}$ ); and between "easy" and "hard" problems in consciousness research (section 4 ).
\end{abstract}

Shimon Edelman does research on vision, language, and consciousness, integrating computational theory and computer modeling with laboratory studies on behavior as well as neurobiological knowledge. http://kybele.psych.cornell.edu/ edelman

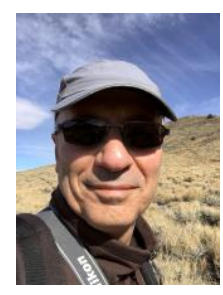

Roy Moyal Is a doctoral student in psychology at Cornell University.

Tomer Fekete does research on
computational approaches to
modeling consciousness, using
dynamical systems to model
spontaneous brain activity, and
trying to understand the link
between network structure and
criticality in cortex.
https://sites.google.com/site/tomerfekete2/

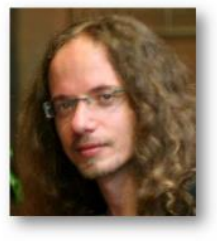




\section{How to put "function" in "functional neurobiology"}

In making their case, Klein \& Barron (2016) (K \& B) focus explicitly and deliberately on one particular level of inquiry:

"To what degree are non-human animals conscious? We propose that the most meaningful way to approach this question is from the perspective of functional neurobiology." [K \& B, p. 1; our emphasis]

But functional neurobiology is only one of the levels on which consciousness - like any other aspect of the computational mind (Edelman, 2008) - needs to be understood: it cannot serve as the sole basis for the kind of argument $K \& B$ are mounting. Ideally, all the levels of the MarrPoggio hierarchy (Marr and Poggio, 1977; Marr, 1982) should be addressed in parallel (Edelman, 2012). ${ }^{1}$ Indeed, one cannot do functional neurobiology without a clear notion of the function in question, even if this notion is still just a hypothesis.

What K \& B offer in the way of function is, very appropriately, Merker's (2005; 2007; 2013) notion of behavioral control being served by information convergence and integration in the midbrain and the thalamus. They also correctly note that integration as such is not an explanation:

"Thus it is not integration per se that matters (as suggested, for example, by Tononi $(2004,2008$; Tononi \& Koch, 2015), but the dynamic and ongoing connection between perception, interoception, associative memory, and motor feedback." [K \& B, p. 5]

Unfortunately, dynamic connection still sounds a lot like (dynamic) integration, which is mystifying. Why mere integration would generate phenomenality (i.e., sentience, feeling) is a valid question, with which Merker's account (which both we and K \& B accept) does not engage. As we argue below in sections $\underline{2}$ and $\underline{3}$, Merker's theory has more to do with what it feels like to be a vertebrate in particular, with vertebrate-type selfhood, as distinguished from awareness in general.

Merker's comparative functional-neurobiological approach can be refocused and sharpened if it is combined with the philosophical analysis of phenomenality by Metzinger $(2003 ; 2004)$. (For a synthesis of the theories of Merker and Metzinger, see Edelman, 2008, ch. 9.) Ultimately a more abstract and perhaps more ambitious understanding - predicated on a resolution of the "hard problem" of consciousness - is called for, and K \& B decline even to consider it:

"We have a similar take on the hard problem: It is difficult because we don't yet have the concepts for assessing what a satisfying answer could even look like." [K \& B, p. 12]

Such reluctance seemed to be the right meta-theoretical move when Crick and Koch (1990) proposed to settle for correlates of consciousness instead of aiming for a standard reductive understanding of it. Now, however, we no longer need to handicap ourselves in this way. There

\footnotetext{
${ }^{1}$ Moreover, this hierarchy must be extended to include evolution, development, and natural behavior (Mayr, 1961; Tinbergen, 1963), which are all interrelated (Laland, Sterelny, Odling-Smee, Hoppitt, and Uller, 2011).
} 
are at least two a priori viable ${ }^{2}$ theories of phenomenality on offer: Tononi's Integrated Information Theory, or IIT (Tononi, 2008; Oizumi et al., 2014), and Fekete and Edelman's Geometric Theory, or GT (Fekete and Edelman, 2011; Fekete, van Leeuwen, and Edelman, 2016). Both these theories are notably computational, which means that the explanations they offer are to a large extent substrate-independent ${ }^{3}$ and may therefore do an even better job unifying the understanding of insect and vertebrate phenomenality.

\section{Corticocentrism, speciesism, and the capacity vs. content distinction}

An all-too-common objection to the idea that insects (or reptiles, or fish) may have phenomenal awareness is based on the "obvious" assumption that awareness requires a cerebral cortex. K \& B expose this assumption as false:

"Note here the important distinction between the capacity for subjective experience and the particular contents of experience at a given time." [K \& B, p. 3]

We agree: the capacity for any type of awareness is more fundamental than the capacity for a full-fledged, specifically human-like (or dog-like, etc.) type of awareness, and it is only the latter for which the cortex may be needed (Merker, 2007). For a computational system, such as the nervous system of an individual member of this or that non-human animal species endowed with what it takes to be aware (see footnote 2) there is something it is like to be that individual - without this something having to be in any way human-like.

Refusing to entertain the notion of a non-human phenomenality amounts to a kind of specieism that has no place in cognitive science or in the philosophy of mind. Moreover, feeling different from a human (say, for lack of a cortex) need not imply less feeling. John W. Campbell, a fabled literary editor, used to urge sci-fi writers to describe something that "thinks as well as a human but not like a human" (Campbell, 1959; see also Edelman, 2008, p. 504); for an apt paraphrase of that memorable line, replace "thinks" with "feels."

We remark that this approach to phenomenality is integral both to the identity theory of mind in philosophy and to the recent cognitive-computational theories (thus, the title of Edelman and Fekete, 2013, is "I am what I am"). One of the original proponents of the identity theory in the 1950s, J. J. C. Smart wrote, "Certainly walking in a forest, seeing the blue of the sky, the green of the trees, the red of the track, one may find it hard to believe that our qualia are merely points in a multidimensional similarity space. But perhaps that is what it is like (to use a phrase that can be distrusted) to be a point in a multidimensional similarity space" (Smart, 2004; the strikeout and the following emphasis ours). This argument also applies, mutatis mutandis, to a bee that is flying along the forest trail.

\footnotetext{
2 The most important a priori constraint on consciousness is that it must be intrinsic to the system in question, that is, it cannot be a matter of attribution by an outside observer; for a discussion of this and other constraints, see Fekete and Edelman, 2011; Edelman and Fekete, 2012; and Oizumi, Albantakis, and Tononi, 2014. These should not be confused with considerations derived by analytical-philosophic means (e.g., Metzinger, 2003).

${ }^{3}$ Not completely; cf. the apparent special status of continuous as opposed to discrete ("digital") dynamics (Fekete and Edelman, 2012; Fekete et al., 2016).
} 


\section{Phenomenality and integration, with and without selfhood}

Admitting that there must be something it is like to be a sensing, evaluating, acting invertebrate has implications for the role, in awareness, of integration - "the dynamic and ongoing connection between perception, interoception, associative memory, and motor feedback" [p. 5]. This is a role that K \& B do not, in our opinion, fully appreciate. Integration is central to both of the theories of phenomenality we singled out earlier as viable: Tononi's IIT and our GT. The latter, in particular, is committed to a specific type of integration dictated by the requirement that the non-trivial multi-scale homology of a trajectory space be "systemic" (Fekete et al., 2016).

Notably, however, neither IIT nor GT entail the existence of a self, which is merely a possible content; content-wise, integration can come in many forms, some of which may lack selfhood altogether. To be clear: we do agree with $\mathrm{K} \& \mathrm{~B}$ that integration in Merker's sense is central to vertebrate phenomenality. It's just that vertebrate phenomenality includes a component $-a$ kind of perception/motivation/action "perspectivality," experienced as being a "self" (Metzinger, 2004; Merker, 2012) - that other types of phenomenality may lack.

If, as it seems to us, self-centered integration is not necessarily central to every form of phenomenality, we are not sure we can accept $K \&$ B's verdict on nematode awareness:

"Because there are no spatial dimensions to a nematode's sensory world, the only way nematodes can interrelate sensory information is by contiguity." [K \& B, p. 10]

No spatial dimensions, therefore no vertebrate-like awareness: granted. But why no awareness at all? Arbitrating this question would require developing a viable quantitative measure of consciousness (Fekete et al., 2016) that does not currently exist.

\section{No hard feelings}

We conclude this brief commentary by revisiting K \& B's stance on the "hard problem" of consciousness. Although they refuse to engage with it (see the passage quoted in section 1), they do admit its existence and its purported difficulty. Methodologically, this stance is counterproductive, because it indulges popular sentiments that would keep consciousness shrouded in mystery rather than see it explained. But this stance is also misguided substantively. This is suggested by the computational theories of phenomenality, as well as by the identity theory of mind, both mentioned earlier. It also follows from another philosophical tradition, whose way of dealing with consciousness is rather more extreme (perhaps too extreme), and whose take on it is exemplified by the following passages from Garfield (2016):

"One of the more puzzling problems in the contemporary industry of consciousness studies is the move from the adjective or the relation to the putative property or phenomenon that is presumed to make it possible to be conscious. One sign of this mystification is the hardness of the so-called 'hard problem,' which, I suspect, derives not from the difficulty of explaining the obviously real phenomenon of consciousness in physical terms, but from the difficulty of 
identifying anything to explain."

"It is not a thing, not an object, not a phenomenon. If we are using the word 'consciousness' not to refer to a thing to be explained, to a feature of the objective world, but just to our Dasein - our mode of being - it is no thing at all, and there is nothing to explain, no problem. Dasein, after all, can never be one more being in the world; it is rather the way in which beings exist." [p. 949]

It seems that this last argument can be made more succinct by coining verbs from nouns that designate sentient agents, as in "to human" or (echoing the title of this commentary), "to bee." That said, a synthesis of the computational and functional-neurobiological approaches to consciousness (which we favor) with the Buddhist and phenomenological ones (which we find intriguing) will have to await future work.

\section{References}

Campbell, J. W. (1959, September). What do you mean... human? Astounding Science Fiction. Editorial.

Crick, F. and C. Koch (1990). Towards a neurobiological theory of consciousness. Seminars in the Neurosciences 2, 263-275.

Edelman, S. (2008). Computing the mind: how the mind really works. New York, NY: Oxford University Press.

Edelman, S. (2012). Vision, reanimated and reimagined. Perception 41, 1116-1127. Special issue on Marr's Vision.

Edelman, S. and T. Fekete (2012). Being in time. In S. Edelman, T. Fekete, and N. Zach (Eds.), Being in Time: Dynamical Models of Phenomenal Experience, pp. 81-94. John Benjamins.

Edelman, S. and T. Fekete (July 2013). I am what I am. In Proceedings of the Annual Conference of the Association for Scientific Study of Consciousness (ASSC-17), San Diego, CA. Extended abstract.

Fekete, T. and S. Edelman (2011). Towards a computational theory of experience. Consciousness and Cognition 20, 807-827.

Fekete, T. and S. Edelman (2012). The (lack of) mental life of some machines. In S. Edelman, T. Fekete, and N. Zach (Eds.), Being in Time: Dynamical Models of Phenomenal Experience, pp. 95-120. John Benjamins.

Fekete, T., C. van Leeuwen, and S. Edelman (2016). System, subsystem, hive: boundary problems in computational theories of consciousness. Frontiers in Psychology 7(1041).

Garfield, J. L. (2016). Reflections on reflectivity: comments on Evan Thompson's Waking, Dreaming, Being. Philosophy East and West 66, 943-951.

Klein, C. and A. B. Barron (2016). Insects have the capacity for subjective experience. Animal Sentience 2016.100.

Laland, K. N., K. Sterelny, J. Odling-Smee, W. Hoppitt, and T. Uller (2011). Cause and effect in biology revisited: Is Mayr's proximate-ultimate dichotomy still useful? Science 334, 15121516.

Marr, D. (1982). Vision. San Francisco, CA: W. H. Freeman. 
Marr, D. and T. Poggio (1977). From understanding computation to understanding neural circuitry. Neurosciences Research Program Bulletin 15, 470-488.

Mayr, E. (1961). Cause and effect in biology. Science 134, 1501-1506.

Merker, B. (2005). The liabilities of mobility: A selection pressure for the transition to consciousness in animal evolution. Consciousness and Cognition 14, 89-114.

Merker, B. (2007). Consciousness without a cerebral cortex: a challenge for neuroscience and medicine. Behavioral and Brain Sciences 30, 63-81.

Merker, B. (2012). From probabilities to percepts: A subcortical 'global best estimate buffer' as locus of phenomenal experience. In S. Edelman, T. Fekete, and N. Zach (Eds.), Being in Time: Dynamical Models of Phenomenal Experience, pp. 37-80. John Benjamins.

Merker, B. (2013). The efference cascade, consciousness, and its self: naturalizing the firstperson pivot of action control. Frontiers in Psychology 4(501), 1-20.

Metzinger, T. (2003). Being No One: The Self-Model Theory of Subjectivity. Cambridge, MA: MIT Press.

Metzinger, T. (2004). The subjectivity of subjective experience: A representationalist analysis of the first-person perspective. Networks 3-4, 33-64.

Oizumi, M., L. Albantakis, and G. Tononi (2014). From the phenomenology to the mechanisms of consciousness: Integrated Information Theory 3.0. PLoS Computational Biology 10(5), e1003588.

Smart, J. J. C. (2004). The identity theory of mind. In E. N. Zalta (Ed.), Stanford Encyclopedia of Philosophy. Stanford University.

Tinbergen, N. (1963). On aims and methods in ethology. Zeitschrift für Tierpsychologie 20, 410433.

Tononi, G. (2008). Consciousness as integrated information: a provisional manifesto. The Biological Bulletin 215, 216-242. 